\title{
Response of Grain Legume Species to Terminal Drought in Timor-Leste ${ }^{\dagger}$
}

\author{
Marcal Gusmao 1,2, Delfim Da Costa ${ }^{1,2}$, Angelo Da Costa Freitas ${ }^{2}$, Kadambot H. M. Siddique ${ }^{3, *}$ \\ and Robert Williams ${ }^{3}$ \\ 1 Centre For Climate Change and Biodiversity, National University of Timor Lorosa'e, Dili, Timor-Leste; \\ marcalgusmao@gmail.com (M.G.); delfimdacosta915@gmail.com (D.D.C.) \\ 2 Department of Agronomy, Faculty of Agriculture, National University of Timor Lorosa'e, Dili, \\ Timor-Leste; angelodafreitas@gmail.com \\ 3 The UWA Institute of Agriculture, The University of Western Australia, 6009 Perth, Australia; \\ rob.williams@agri.tl \\ * Correspondence: kadambot.siddique@uwa.edu.au \\ + Presented at the Third International Tropical Agriculture Conference (TROPAG 2019), Brisbane, Australia, \\ 11-13 November 2019.
}

Published: 8 April 2020

\begin{abstract}
Growth, development and yield of three-grain legumes (mung bean [F1], soybean [F2] and grass pea [F3]) following rice crop to enhance grain production was studied in a paddy field in the northern Timor-Leste. A split plot design was used with three water treatments (well-watered [W0], water withheld at flowering [W1] and after germination [W2]). Interaction between water treatments and species on dry matter production $(p<0.001)$ and seed yield $(p=0.005)$ was observed. In control, the highest seed yield was F1 (1.2 t/ha) followed by F2 (1.1 t/ha) and F3 (0.4 t/ha) respectively. There was a steady reduction in seed yield in F1 from W0 to W2, but almost fifty percent reduction in F2 under W1 and W2 compared to W0. F3 had little difference between water treatments. The W1 and W2 reduced number of filled pods per plant in all species compared to control (W0). Between the species, F3 had the highest filled pods per plant followed by F2 and F3. The W1 and W2 reduced seeds per pod of F1; however, it did not effect F2 and F3. There were interactions between water treatment and species on 100 seeds weight. The heaviest seeds were in F2 in the control plants, but in the F2 drought treatments (W1 and W2) seed weight were less than F3. The lowest seed weight was in F1, but there was no impact of the terminal droughts on its seed weight.
\end{abstract}

Keywords: climate change; adaptation; water use; drought; grain legumes; paddy field

Conflicts of Interest: The authors declare no conflict of interest.

(C) 2020 by the authors. Licensee MDPI, Basel, Switzerland. This article is an open access article distributed under the terms and conditions of the Creative Commons Attribution (CC BY) license (http://creativecommons.org/licenses/by/4.0/). 